\title{
Observation of Environmental Stress Cracking in Polymethylmethacrylate by Using the Chemiluminescence Method
}

\author{
Yuji Higuchi \\ Energy Technology Laboratories, Osaka Gas Co., Ltd., Osaka, Japan \\ Email: belkeviz@hotmail.com
}

Received 26 August 2015; accepted 27 November 2015; published 30 November 2015

Copyright (C) 2015 by author and Scientific Research Publishing Inc.

This work is licensed under the Creative Commons Attribution International License (CC BY). http://creativecommons.org/licenses/by/4.0/

c) (i) Open Access

\section{Abstract}

Polymethylmethacrylate (PMMA) is highly regarded for its transparency, and is used in such products as cameras and Video Tape Recorders as plastic lenses to take advantage of its excellent optical properties. Also, it is used in numerous other industrial fields like automobile lamp lenses, billboards, and lighting equipment. The phenomenon of environmental stress cracking is known to occur in PMMA due to ethanol, and there are cases when this may become a factor which causes damage of molded products. In the present paper, upon close observation by using the method of chemiluminescence in order to elucidate the mechanism by which this environmental stress cracking occurs, we report that we are able to capture the formation of a radical at the moment of cracking.

\section{Keywords}

Polymethylmethacrylate, Environmental Stress Cracking, Chemiluminescence, Radical

\section{Introduction}

Plastic components are used in various kinds of equipment and machinery, but depending on the environmental factors involved, various kinds of degradations may arise. Among these is environmental stress cracking, which accounts for one-third of all types of such degradations [1], making it the most representative degradation phenomenon. Environmental stress cracking occurs when an environmental liquid that has come into contact with a plastic component in which there is inherent residual strain built up from the molding process permeates into the plastic component, causing swelling, and then the pressure is released by the formation of a crack. It is not the cleavage of a covalent bond of molecules but the dissociation of the Van der Waals force of an inter-molecular 
chain; therefore, it is characteristic of the resulting fractured surface to appear mirror-like, and it is easy to distinguish fractured surfaces according to whether there is a fatigue, ductile, or some other kind of fracture. As for a plastic's environmental stress cracking resistance, its compatibility with a given environmental liquid is a dominant factor, and as a means of evaluating compatibility, solubility parameters are used. That is to say, it can be thought that the greater the difference between a plastic's and an environmental liquid's solubility parameter values, the less likely it is that environmental stress cracking will occur. In such ways, methods of taking measures against environmental stress cracking by using solubility parameters, and inferences regarding the causes of fractures by observing surface cracks [2]-[6], are being devised. However, in terms of analytical study of the phenomenon of cracking, analysis that focuses on the moment of cracking is necessary, yet due to problems like the lack of a measurement facility such research has to date been largely left undone.

The chemiluminescence method is a technique for detecting low light emissions down to the single-photon level. The capturing of low light emitted from specimens is used for various purposes, including: 1) high sensitivity direct detection of peroxide $(\mathrm{ROOH})$, which is an intermediate product released during oxidation reactions; 2) detection of cavitation, reactive oxygen, and so forth; 3) and detection of trace components by using luminescent reagents [7]-[10]. In particular, because of the fact that the chemiluminescence method makes possible the capture of the extreme early stage changes of the oxidation degradation process, it is utilized as an indicator of degradation due to thermal history during plastic molding, in checking recyclability or in other inspections upon the receipt of materials, and in evaluation of antioxidative substances, among other uses. In the chemiluminescence method, the quantity of peroxide produced during oxidation is measured by detecting energy that radiates as light when excited-state carbonyl $\left(\mathrm{C}=\mathrm{O}^{*}\right)$, yielded by a biomolecular reaction upon peroxide decomposing and turning into a peroxy radical (ROO), returns to the ground state $(\mathrm{C}=\mathrm{O})$. At the same time, light emission due to such phenomena as cavitation and friction can also be detected. Soyama et al. have detected low light emission from cavitation, and speculate that the mechanism by which luminescence occurs during this process is a hydroxyl radical $(\cdot \mathrm{OH})[11]$.

In environmental stress cracking in plastics, an environmental liquid seeps into the plastic, resulting in swelling, and this causes a crack to occur. We postulated that at that time a radical may form. Based on this, for the purpose of capturing the formation of that radical, we carried out an observation of the phenomenon of environmental stress cracking using the chemiluminescence method.

\section{Experiment}

It is known that environmental stress cracking occurs in Polymethylmethacrylate (PMMA) due to alcohol. In this experiment, we placed a $50 \mathrm{~mm}$ long, $10 \mathrm{~mm}$ wide, $2 \mathrm{~mm}$ thick test specimen of commercial PMMA which had been molded into a curved state (arch configuration) in a $\varphi 50 \mathrm{~mm}$ chemiluminescence measuring cell, then stored it in a sample chamber with the relevant measuring equipment.

For our measurements, we used a chemiluminescence image processing device with a High Sensitivity CCD camera (CLA-IS1: Tohoku Electronic Industrial Co., Ltd.). A diagrammatic illustration of the device is shown in Figure 1. In order to enhance the sensitivity of the chemiluminescence measurement, we added $1.13 \mathrm{mM}$ of luminol to the $200 \mu \mathrm{l}$ of ethanol. The camera's exposure time was set at thirty seconds, after preliminary observations had also been conducted at five and ten seconds.

After initiating the measurements, from outside the sample chamber we used a syringe to drip ethanol onto the specimen in order to cause environmental stress cracking to occur in the portion being measured by our equipment.

\section{Results and Discussion}

Figure 2 shows a series of photographs depicting the damage process. Immediately after the dripping of the ethanol, countless cracks began forming in the PMMA while it emitted a creaking sound. The arch configuration of the PMMA then collapsed, as a damage phenomenon occurred. Figure 3 shows the chemiluminescence images from when the environmental stress cracking was caused to occur in the measuring cell. Figure 3(a) is from before the drip; Figure 3(b) is from immediately after the drip; Figure 3(c) is from a short time later, after the drip; and Figure 3(d) shows the cell as of when the processing device was opened following the experiment. As shown in Figure 3(b), immediately after the ethanol was dripped a strong luminescence was ascertained in one portion of the specimen. Such emission of light did not appear in the before and after Figure 3(a) and Figure 3(c), 


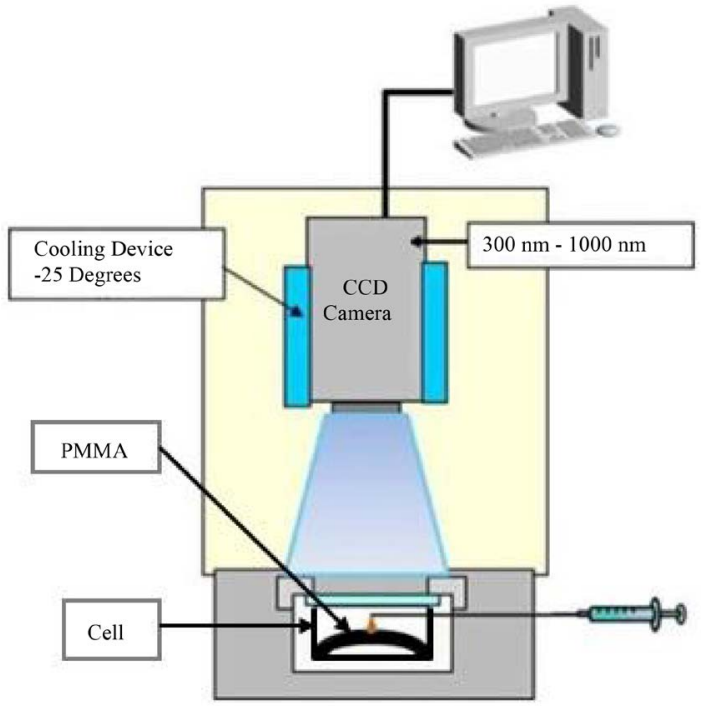

Figure 1. Chemiluminescence image processing device.

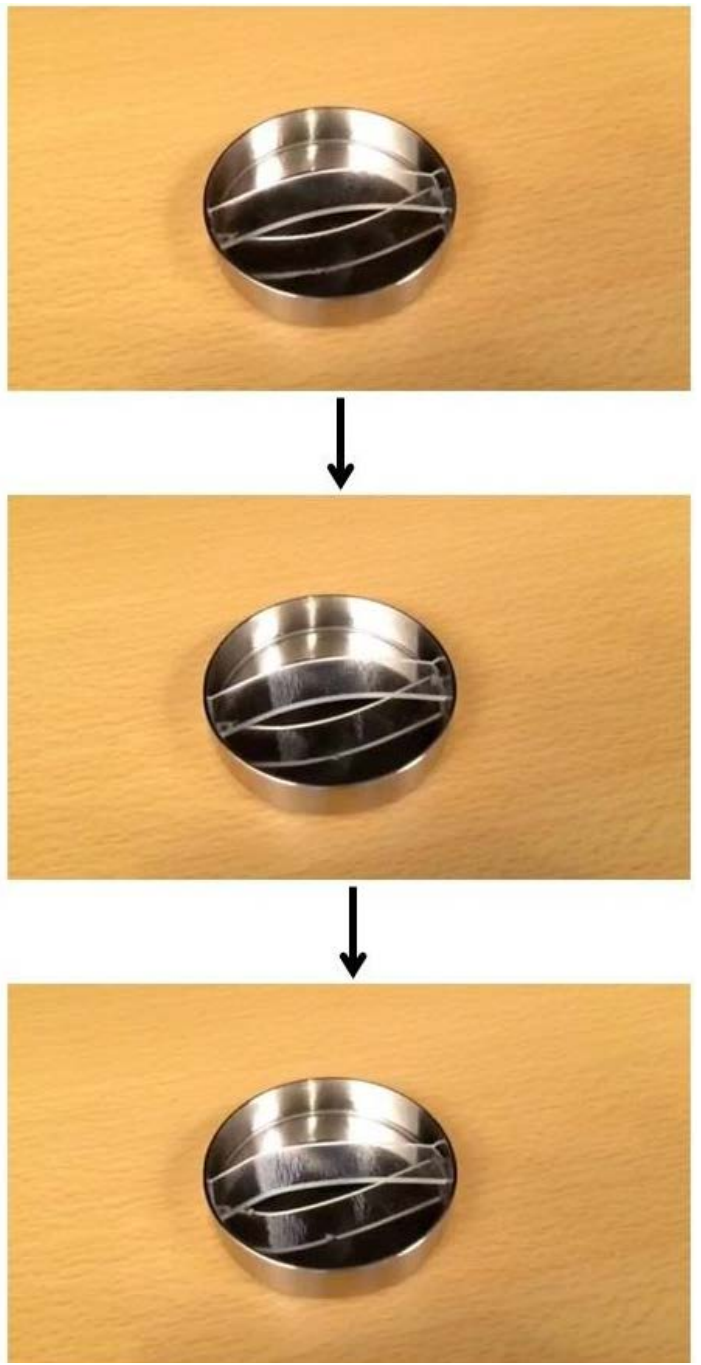

Figure 2. Photographs of the damage process. 


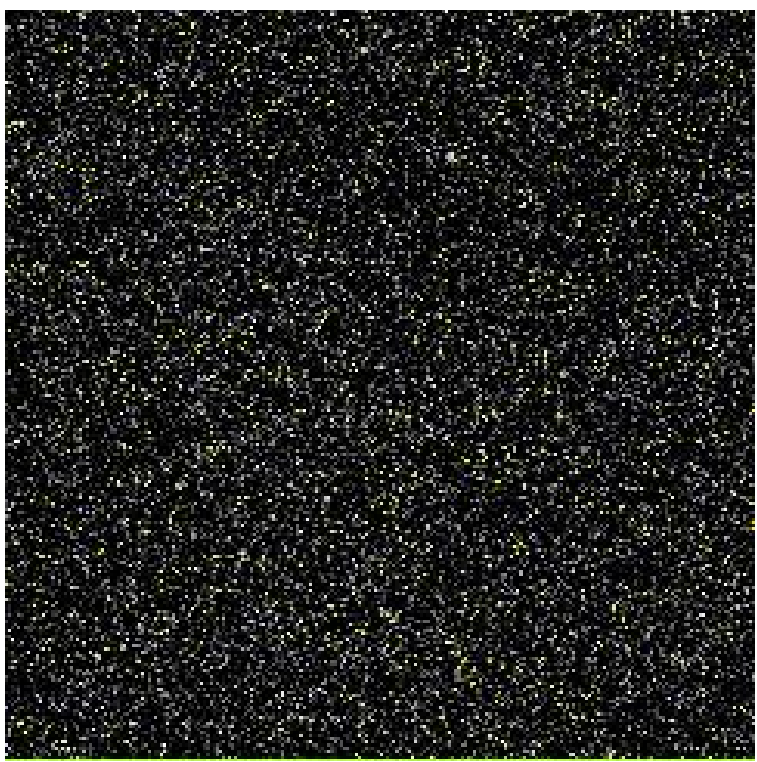

(a)

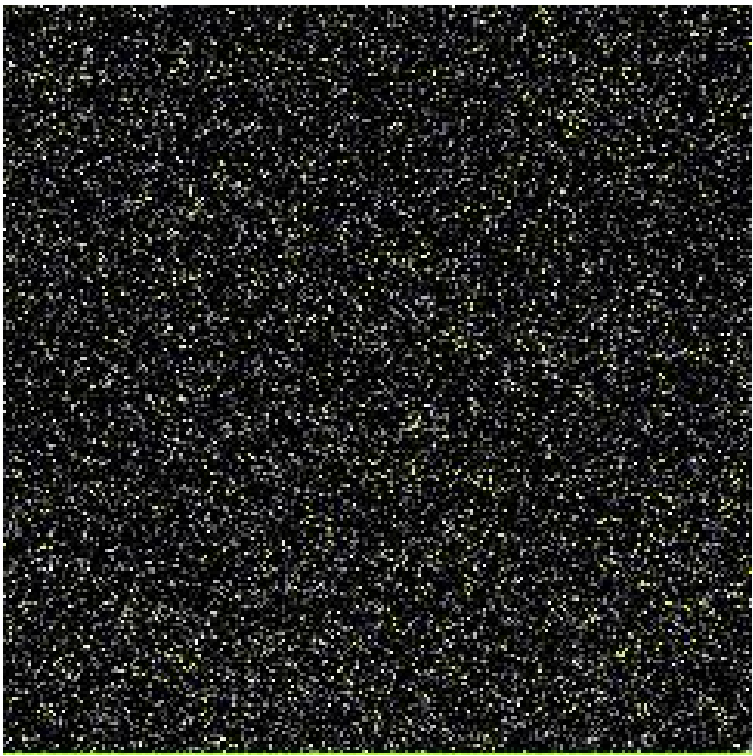

(c)

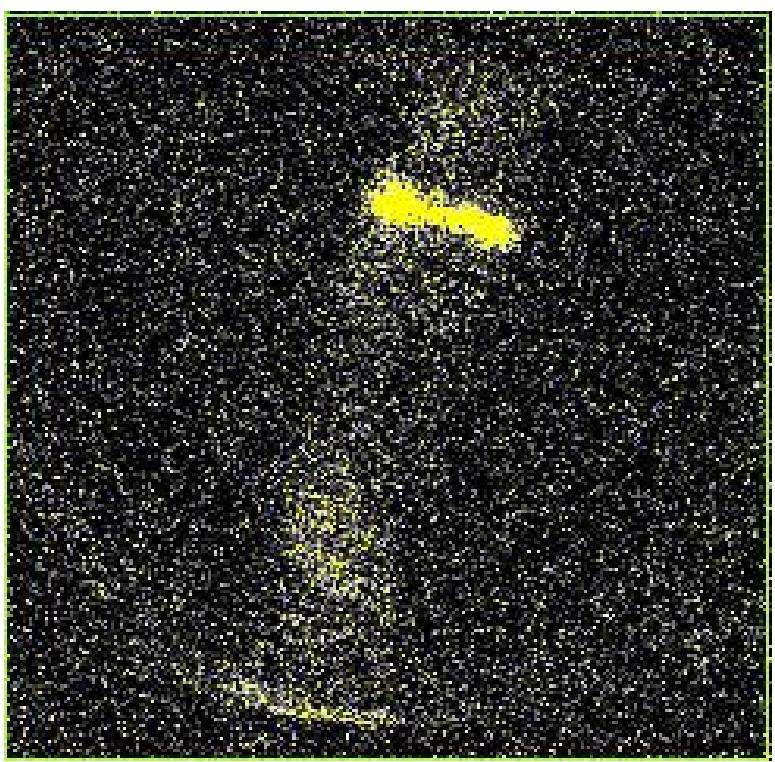

(b)

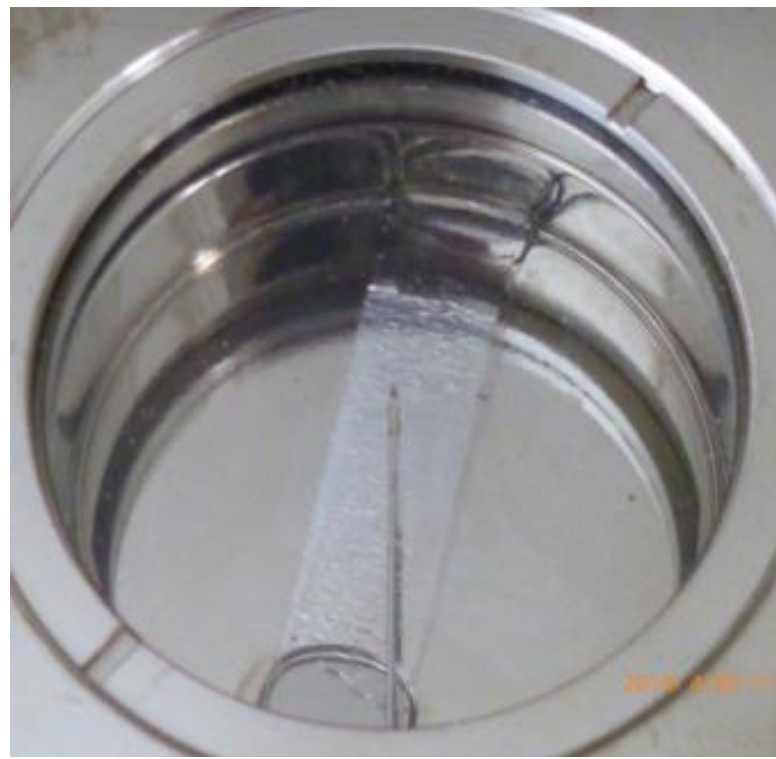

(d)

Figure 3. Chemiluminescence and after experiment images. (a) Before drip; (b) Immediately after dripping; (c) After drip; (d) After experiment.

respectively. Also, due to environmental stress cracking the PMMA specimen was split into two parts in the way shown in Figure 3(d), and we were able to confirm that the point at which the split occurred corresponded to the portion that had shown the intense light emission in Figure 3(b). From this, we can say that when the cracking and split occurred in the PMMA specimen a radical formed, and that we were able to capture luminol oxidized by means of that radical as emitted light using the chemiluminescence apparatus.

\section{Conclusion}

In conducting our measurements regarding the formation of a radical at the occurrence of environmental stress cracking due to ethanol in PMMA using the chemiluminescence method, we were able to verify light emission centered in the portion where the cracking and splitting took place. This appears to have been a capturing of the formation of the radical that accompanies such cracking and splitting. The method used in this paper can be ap- 
plied to the evaluation of plastic parts affected by environmental liquids and stress. Such parts include, but are not limited to, gas stove knobs and remote control units.

\section{Acknowledgements}

I would like to express my gratitude to Dr. R. Yamada (Tohoku Electronic Industrial Co., Ltd., Japan) for her contributions to this research through her invaluable support during experiments and discussions.

\section{References}

[1] Woishnis, W.A. and Wright, D.C. (1994) Select Plastics to Avoid Product Failure. Advanced Materials and Processes, 12, 39-40.

[2] Arnold, J.C. (1998) The Effects of Diffusion on Environmental Stress Crack Initiation in PMMA. Journal of Materials Science, 33, 5193-5204. http://dx.doi.org/10.1023/A:1004431920449

[3] Lagaron, J.M., Pastor, J.M. and Kip, B.J. (1999) Role of an Active Environment of Use in an Environmental Stress Crack Resistance (ESCR) Test in Stretched Polyethylene: A Vibrational Spectroscopy and a SEM Study. Polymer, 40, 1629-1636. http://dx.doi.org/10.1016/S0032-3861(98)00406-6

[4] Lagaron, J.M., Dixon, N.M., Reed, W., Pastor, J.M. and Kip, B.J. (1999) Morphological Characterization of the Crystalline Structure of Cold-Drawn HDPE Used as a Model Material for the Environmental Stress Cracking (ESC) Phenomenon. Polymer, 40, 2569-2586. http://dx.doi.org/10.1016/S0032-3861(98)00500-X

[5] Kurelec, L., Teeuwen, M., Schoffeleers, H. and Deblieck, R. (2005) Strain Hardening Modulus as a Measure of Environmental Stress Crack Resistance of High Density Polyethylene. Polymer, 46, 6369-6379. http://dx.doi.org/10.1016/j.polymer.2005.05.061

[6] Cazenave, J., Seguela, R., Sixou, B. and Germain, Y. (2006) Short-Term Mechanical and Structural Approaches for the Evaluation of Polyethylene Stress Crack Resistance. Polymer, 47, 3904-3914. http://dx.doi.org/10.1016/j.polymer.2006.03.094

[7] Jipa, S., Osawa, Z., Otsuki, H. and Nishimoto, M. (1997) Chemiluminescence Assessment of the Effectiveness of Some Phenolic Antioxidants for Heat Stabilization of Irradiated LDPE. Polymer Degradation and Stability, 56, 45-53. http://dx.doi.org/10.1016/S0141-3910(96)00196-6

[8] Setnescu, R., Jipa, S. and Osawa, Z. (1998) Chemiluminescence Study on the Oxidation of Several Polyolefins: I. Thermal-induced Degradation of Additive-free Polyolefins. Polymer Degradation and Stability, 60, 377-383. http://dx.doi.org/10.1016/S0141-3910(97)00096-7

[9] Yamada, R. (2010) Development of Chemiluminescence Detectors for the Research of Polymer Oxidation and Other Applications. Project about the Preservation of Plastic Artefacts in Museum Collections: Recent Advances in the Use of Chemiluminescence for Conservation Science, International Workshop, Slovakia, 38-39.

[10] Yamada, R. and Myerscough, T. (2013) Polymer Oxidation Detection Using Ultra-Sensitive Chemiluminescence Analysis. Proceedings of the 30th Polymer Degradation Discussion Group Meeting, Paris, 37-38.

[11] Soyama, H. and Muraoka, T. (2011) Chemical Reactor Using Radical Induced by a Cavitating Jet. Proceedings of the 20th International Conference on Water Jetting, 259-267. 